\title{
O USO DE MATERIAIS HIBRIDOS OU NANOCOMPÓSITOS COMO REVESTIMENTOS ANTICORROSIVOS DO
} AÇO

\author{
Guilherme Augusto Bertelli Fernandes Clemente ${ }^{\mathrm{a}, *,(\odot), ~ G u s t a v o ~ H e n r i q u e ~ G o n c ̧ a l v e s ~}{ }^{\mathrm{b}}$, Eduardo José Nassar ${ }^{\mathrm{a}}$, Eduardo \\ Ferreira Molina ${ }^{a}$ e Lucas Alonso Rocha ${ }^{a}$ \\ aDepartamento de Química, Universidade de Franca, 14404-600 Franca - SP, Brasil \\ bDepartamento de Ciências, Universidade de Ribeirão Preto, 14096-900 Ribeirão Preto - SP, Brasil
}

Recebido em 23/10/2020; aceito em 12/03/2021; publicado na web em 16/04/2021

\begin{abstract}
THE USE OF HYBRID OR NANOCOMPOSITE MATERIALS AS STEEL ANTICORROSIVE COATINGS. The search had as the goal to present and reflect the hybrid materials as an alternative for anticorrosive coatings of metallic surfaces, such as steel. For comparison purposes, different types of anti-corrosion coatings capable of protecting metallic surfaces, such as steel, from oxidation action were presented. Steel is a metallic material widely used by industry in different types of segments, and its corrosion is a pathology responsible for its functional loss, causing losses in its use. Through a qualitative, bibliographic and exploratory research, based on academic works, it was presented that hybrid materials or nanocomposites prove to be efficient as anticorrosive coatings capable of protecting steel against oxidation.
\end{abstract}

Keywords: hybrid materials; nanocomposites; anti-corrosion coatings; steel.

\section{INTRODUÇÃO}

A corrosão em superfícies metálicas vem causando diversos prejuízos em setores industriais que utilizam este tipo de material, o que torna importante o desenvolvimento de tecnologias que possibilitem resolver os problemas relacionados à corrosão.

No Brasil, $76 \%$ do aço utilizado em estruturas metálicas são reutilizados ou reciclados quando chegam ao final de sua vida útil e necessitam de ser substituídos, sendo que os novos produtos de aço provenientes da reciclagem não possuem suas propriedades originais alteradas, garantindo sua funcionalidade, destacando que todos os todos os resíduos de aço podem ser $100 \%$ reciclados para diversas finalidades, inclusive para o material de aço estrutural, que pode ser $98 \%$ recuperado e reutilizado. ${ }^{1}$

Estima-se que são gastos anualmente, no Brasil, US\$ 10 bilhões com reparos de estruturas metálicas devido à corrosão, apesar do reaproveitamento do material através da reciclagem. ${ }^{2}$

A corrosão é um fenômeno possivelmente espontâneo de deterioração de materiais metálicos ou não metálicos, causando a perda do material e a redução de sua vida útil que, para os metais, está relacionada com a oxidação e com a redução da superfície do material em contato com o agente corrosivo, o que torna importante o interrompimento do processo corrosivo, para que as perdas não sejam críticas. ${ }^{3,4}$

Alguns métodos vêm sendo propostos para controlar os problemas causados pela corrosão, assim como o uso de película de tinta epóxi, a aplicação de revestimentos emborrachados, cerâmicos e plásticos, e as técnicas de pintura industrial, que se destacam por apresentar maior versatilidade, fácil aplicação e fácil manutenção, além de serem de baixo custo, o que torna esta técnica uma ótima alternativa como revestimento anticorrosivo, porém, existem pinturas industriais anticorrosivas que não apresentaram eficiência na proteção de superfícies metálicas em ambientes altamente corrosivos. ${ }^{5,6}$

Os materiais poliméricos adicionados a materiais híbridos são capazes de otimizar as características dos materiais, tornando-os multifuncionais e com propriedades singulares, como boa aderência,

*e-mail: engenheirocivilguilherme@yahoo.com.br resistência mecânica, resistência química, resistência à corrosão e estabilidade dimensional. O material polimérico epóxi, que é capaz de melhorar a aderência e a resistência química à corrosão dos materiais, possibilita o seu uso como um revestimento anticorrosivo em superfícies metálicas. ${ }^{7}$

Este artigo tem a finalidade de apresentar e refletir sobre os materiais híbridos como uma alternativa para revestimentos anticorrosivos de superfícies metálicas, como o aço, por meio de resultados e discussões de artigos oriundos prioritariamente do campo da química, obtidos por meio de uma coleta de um levantamento bibliográfico, através do uso de portais de periódicos SciELO, Periódicos CAPES e Portal MEC, utilizando as palavras chaves: materiais híbridos, nanocompósitos, revestimentos, anticorrosivos e aço.

Trata-se de uma pesquisa de caráter exploratório-descritivo, com uma pesquisa exploratória focando em proporcionar maior familiaridade com o problema, com vista a torná-lo mais explícito ou a constituir hipóteses. Pode-se dizer que esta pesquisa tem como objetivo principal o aprimoramento de ideias ou relato de intuições. Seu planejamento é, portanto, bastante flexível, de modo que possibilite a consideração dos mais variados aspectos relativos ao fato estudado. ${ }^{8}$

Enfim, a pesquisa é qualitativa por apresentar materiais híbridos como uma alternativa para revestimentos anticorrosivos de superfícies metálicas, como o aço.

\section{O AÇO E A CORROSÃO}

O aço é utilizado pela indústria de variadas formas e em diversos segmentos. Esse material pode ser utilizado como ligas metálicas ou como elementos estruturais em segmentos como construção civil, petroquímicas, indústrias de petróleo, entre outras. Devido ao fato de que aço pode sofrer degradação com o tempo, as indústrias relacionadas com esse material são afetadas, tornando importante a adoção de medidas de preservação de degradação desse material. ${ }^{9}$

Pensando na prevenção da degradação do aço, é importante que os materiais metálicos possuam propriedades de resistência as adversidades do ambiente ou devam ser tratados com métodos e 
mecanismos químicos de proteção contra os meios de deterioração do aço, como a corrosão. ${ }^{9}$

$\mathrm{O}$ aço-carbono ou aço comum é uma liga ferro-carbono contendo entre $0,008 \%$ a $2,11 \%$ de carbono, além de outros elementos residuais, resultante de um processo de fabricação em que o limite de $0,008 \%$ está relacionado à máxima solubilidade do carbono no ferro à uma temperatura ambiente e o limite de $2,11 \%$ está relacionado à máxima quantidade de carbono que se dissolve no ferro à uma temperatura de $1148{ }^{\circ} \mathrm{C}$, porém, os aços-liga são aços que apresentam outros elementos de liga ou contém elementos residuais além dos considerados normais, como o manganês, silício, fósforo e enxofre. ${ }^{10}$

$\mathrm{O}$ aço mais utilizado para estruturas construtivas como liga metálica é o aço carbono, graças suas excelentes propriedades mecânicas. Esse material é definido como uma liga de ferro carbono, enxofre, fósforo, silício, alumínio e cobre. ${ }^{11}$

O processo de corrosão do aço é o resultado de reações químicas do material com o ambiente, ocasionando assim a deterioração de suas propriedades. O oxigênio, hidrogênio e/ou água envolvem os processos de oxidação e de redução que abrangem a corrosão. Devido a esse fato, torna-se importante a proteção da superfície do material para que se garanta a aparência superficial, por meio de técnicas de revestimentos protetores de superfícies. ${ }^{12}$

Os aços comuns são constituídos por mais de $97 \%$ de Fe, com até $2 \%$ de $\mathrm{C}$ e demais elementos resultantes do processo de fabricação, e o ar atmosférico representa o meio ao qual os materiais metálicos estão mais frequentemente expostos, e a oxidação do $\mathrm{Fe}(\mathrm{s})$ acontece devido sua característica termodinamicamente instável na presença de $\mathrm{O}_{2}$ (g) que, quando agindo em conjunto com o $\mathrm{H}_{2} \mathrm{O}(\mathrm{g})$, torna o meio atmosférico mais agressivo aos aços, originando uma camada porosa de produtos de corrosão conhecida como ferrugem. ${ }^{13}$

O processo de degradação de elementos metálicos conhecido como corrosão é causado pela oxidação de átomos na superfície do material, conforme as reações mostradas na Figura 1, em que é possível entender os aumentos na densidade de cátions e na liberação de elétrons na interface eletrodo e eletólitos, e para que ocorra o progresso de forma contínua da oxidação, é necessária a transferência dos eletrodos produzidos para a área interfacial onde ocorre a redução de $\mathrm{O}_{2}$ ou $\mathrm{H}^{+}$, na chamada área catódica, o que causa um aumento na densidade de ânions, como o $\mathrm{OH}^{-}$, ou na diminuição da densidade de cátions, como $\mathrm{o}^{+}$, na interface eletrodo e eletólitos, resultando em pares de áreas anódicas e catódicas considerados como células de corrosão. ${ }^{14}$

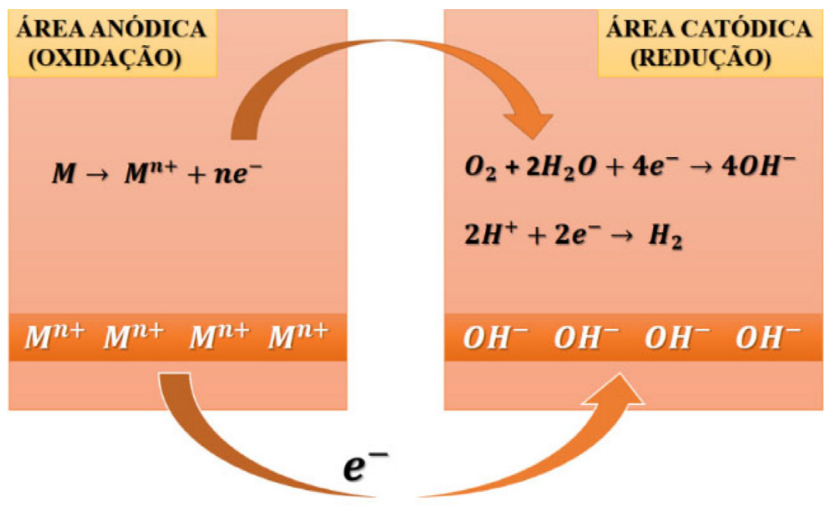

Figura 1. Esquemática das reações típicas de corrosão em uma interface metal-água

A corrosão pode ser definida como um processo químico ou eletroquímico, destrutivo e não intencional de um metal, iniciado na superfície do material, através de reações de oxirredução, com a ocorrência de troca de elétrons entre os elementos químicos que convertem o metal de base em óxidos, hidróxidos ou sais. ${ }^{15}$
A oxidação é o processo químico em que o elemento perde elétrons, e a redução química é o processo de ganho de elétrons por um elemento ou espécie química, já a corrosão de natureza química, acontece sem que haja a troca de elétrons através da ação de produtos químicos, como o que ocorre com estruturas de concreto armado em contato com determinados sais que prejudicam os materiais da estrutura. ${ }^{15}$

Desta forma, a corrosão como a deterioração dos materiais, que em relação aos aços, acontece de forma espontânea por meio de um processo químico ou eletroquímico influenciado pelas condições do meio corrosivo e pela natureza do material, e para minimizar os prejuízos causados pela corrosão, os materiais podem passar por prétratamentos inibidores de corrosão, fornecendo proteção anticorrosiva e aumentando a vida útil do material. ${ }^{16}$

Outro tipo de corrosão é a microbiológica, que está vinculada a formação de biofilmes formados por comunidades de microrganismos inseridos em uma matriz polimérica extracelular associada a uma superfície. Esse processo de corrosão pode ser intensificado por microrganismos presentes e expostos à ação do metabolismo realizado na área superficial do material, como por exemplo na produção de material polimérico extracelular e na redução de íons sulfato a sulfito, e pode ser combatido por meio da aplicação de biocidas, contendo sais quaternários de amônio. ${ }^{9}$

O processo de corrosão é responsável pela deterioração das propriedades estruturais dos metais, por meio dos processos de oxidação e de redução, envolvendo oxigênio, hidrogênio e/ou água em meio condutor, o que torna importante a viabilização econômica de tipos de proteção contra corrosão de materiais metálicos. ${ }^{12}$

\section{MATERIAIS HÍBRIDOS OU NANOCOMPÓSITOS E A CORROSÃO}

Os materiais híbridos ou nanocompósitos são híbridos de materiais que envolvem compostos orgânicos e inorgânicos. Estudos mostram que materiais híbridos preparados a partir de nanocompósitos poliméricos e argila montmorilonita de origem natural apresentaram alta capacidade de delaminação, alta resistência a solventes e estabilidade térmica, e que estudos com partículas inorgânicas do composto de fosfato melhoraram a resistência dos materiais de revestimento à corrosão, também mostraram que o uso dos minerais filossilicatos (argilas) melhoram a capacidade de adsorção dos materiais, o que faz entender que a utilização de compostos de materiais orgânicos e inorgânicos são importantes para a obtenção de materiais com funcionalidades diversas e potencializadas. ${ }^{16}$

Material hibrido formado a partir de um polímero condutor, como a polianilina (PAni), mostra eficiência de proteção do revestimento de $80 \%$ em relação aos materiais não híbridos, confirmando que o revestimento a partir de um material hibrido promove maior proteção contra a corrosão, o uso de nanopartículas ou materiais híbridos proporcionam a formação de pontos de ancoragem que otimizam à adesão de tintas de revestimento de proteção contra corrosão, em superfícies metálicas, além de misturas de nanopartículas de prata e cério promoverem a evolução na textura e morfologia do revestimento em filmes. ${ }^{12}$

Revestimentos como os de polianilina apresentaram características uniformes e é extremamente aderente, com grande potencial de proteção de ligas de alumínio contra a corrosão, quando exposto ao $\mathrm{NaCl}$ aquoso. Tal propriedade mostrou, ainda, ter melhor desempenho na proteção contra a corrosão, com a incorporação de sal de esmeraldina quimicamente sintetizada, por meio de desdopagem e dopagem química, em compósitos contendo massa de polianilina. ${ }^{17,18}$

A nanotecnologia é responsável pelo aprimoramento de diversos materiais, que sofrem com a presença de poluentes e da umidade na 
atmosfera causadores de mecanismos de deterioração e corrosão. O processo de corrosão é espontâneo e causador da destruição de elementos metálicos, em que o oxigênio e o ferro dissolvidos em água participam de uma reação óxido-redução, ocorrendo primeiramente a oxidação e logo após a redução, como mosta as Equações 1 a 3.19

$$
\begin{gathered}
2 \mathrm{Fe}+2 \mathrm{H}_{2} \mathrm{O}+\mathrm{O}_{2} \rightarrow 2 \mathrm{Fe}_{2}+4 \mathrm{OH}^{-} \rightarrow 2 \mathrm{Fe}(\mathrm{OH})_{2} \\
2 \mathrm{Fe} \rightarrow 2 \mathrm{Fe}^{2+}+4 \mathrm{e}^{-}(\text {reação anódica }) \\
\mathrm{O}_{2}+2 \mathrm{H}_{2} \mathrm{O}+4 \mathrm{e}^{-} \rightarrow 4 \mathrm{OH}^{-} \text {(reação catódica) }
\end{gathered}
$$

Para que a corrosão de materiais metálicos seja evitada existem estratégias inibidoras da oxidação, como a utilização de revestimentos orgânicos e inorgânicos que servem de barreira ao acesso de contaminantes ao metal, garantindo a durabilidade da estrutura metálica e a sua resistência à umidade.

Resultados obtidos de acordo com a literatura, ${ }^{19}$ nanorreservatórios de hidróxidos duplos lamelares HDL, adicionados à resina epóxi, intercalam-se em suas lamelas íons inibidores de corrosão, sendo que os HDL's mais estudados na inibição da corrosão são do tipo $\mathrm{Zn}-\mathrm{Al}-\mathrm{X}^{\mathrm{n}}$, em que $\mathrm{X}^{\mathrm{n}}$ representa um ânion com valência n. ${ }^{19}$

Em estudo o HDL do tipo $\mathrm{Zn}-\mathrm{Al}-\mathrm{NO}_{2}^{-}$, em que no domínio interlamelar se encontram os ânions do inibidor de corrosão nitrito $\left(\mathrm{NO}_{2}{ }^{-}\right)$, o nitrito funciona como um inibidor anódico, reduzindo-se e se absorvendo-se na superfície do metal, liberando íons $\mathrm{O}_{2}{ }^{-}$, que interagem com os íons de Fe (III), em soluções neutras e básicas, resultando em compostos conforme as Equações 4 e 5.20

$$
\begin{gathered}
2 \mathrm{NO}^{2-}+4 \mathrm{e}^{-} \rightarrow \mathrm{N}_{2} \mathrm{O}+3 \mathrm{O}^{2-} \\
2 \mathrm{Fe}^{2+}+2 \mathrm{OH}^{-}+2 \mathrm{NO}^{2-} \rightarrow 2 \mathrm{NO}+\gamma \mathrm{Fe}_{2} \mathrm{O}_{3}+\mathrm{H}_{2} \mathrm{O}
\end{gathered}
$$

Dessa forma, é possível entender que os materiais híbridos são importantes na proteção contra a corrosão, como materiais anticorrosivos, garantindo, assim, que os materiais metálicos sujeitos à corrosão possam manter suas características físicas e químicas integras por um tempo maior, o que mostra que esses materiais híbridos, além de permitirem características que possam resolver problemas com corrosão, também são capazes de serem funcionalizados para resolves diversos outros tipos de problemas. ${ }^{12}$

\section{PROCESSOS INIBIDORES DE CORROSÃO}

As soluções de ácido fosfórico, com metais dissolvidos (zinco, níquel, manganês), serviram de base para os processos clássicos de pré-tratamentos contra corrosão, portanto, novos tratamentos mais ecológicos à base de nanopartículas isentas de metais bioacumulativos e fósforo vêm sendo preparados, como, por exemplo, o processo de fosfatização, que vem sendo substituído por processos à base de nanotecnologia, através da deposição de filmes finos nanocerâmicos à base de zincônia e alumina, facilitando, assim, a sintetização e a aplicação do material em substratos metálicos e apresentando um resultado satisfatório na inibição da corrosão do aço. ${ }^{21}$

Revestimentos alquídicos com pigmentos de cromo hexavalente são eficientes como materiais protetores contra a corrosão de superfícies metálicas, e destaca a necessidade de estudos de revestimentos protetores inteligentes, com a funcionalidade de autocura, anti-incrustação, autolimpeza e antifricção, sendo eficazes aos diferentes ataques corrosivos. ${ }^{12}$

Materiais híbridos apresentam eficiência como revestimentos de proteção ao ataque da corrosão em superfícies metálicas, assim como compósitos preparados de PAni/nanotubos- $\mathrm{TiO}_{2}$, através de polimerização in situ de anilina seguida de sulfonação com ácido clorossulfônico em um solvente inerte e por hidrólise em água, mostrar-se-ão funcionais para a proteção corrosiva em aço carbono e aço carbono soldado, e resultando em um material com aderência e propriedades anticorrosivas satisfatórias. ${ }^{22}$

A Figura 2 mostra a morfologia do PAni (Figura 2a) e do PAni/n- $\mathrm{TiO}_{2}$ (Figura 2b) do um compósito de maior espessura de cobrindo no aço. Em ambos os casos, o aço foi totalmente coberto por uma camada uniforme de polímero, e o n- $\mathrm{TiO}_{2}$ não foi observado, indicando que os nanotubos estavam imersos em a matriz polimérica (Figura 2b). Para esclarecer a presença de $n-\mathrm{TiO}_{2}$ no revestimento, um mapeamento da superfície foi realizado (Figura $2 \mathrm{c}$ ). ${ }^{22}$

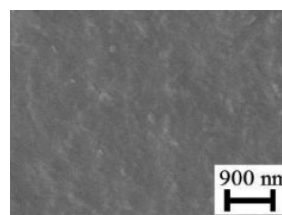

(a)

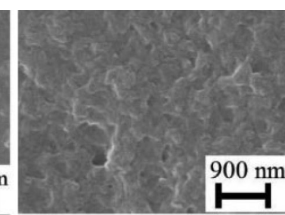

(b)

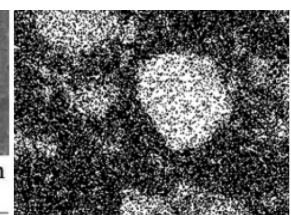

(c)
Figura 2. Estudos morfológicos: (a) MEV do revestimento PAni; (b) MEV do revestimento $\mathrm{PAni} / \mathrm{n}-\mathrm{TiO}_{2}$; e (c) mapeamento de $n$-TiO $\mathrm{O}_{2}$ na amostra PAni $/ \mathrm{n}-\mathrm{TiO}_{2}^{22}$

O comportamento anticorrosivo dos revestimentos PAni-1 e $\mathrm{PAni} / \mathrm{n}-\mathrm{TiO}_{2}$ foram determinados usando curvas de polarização em meio de cloreto de sódio a 3\%. A Figura 3 mostra as curvas de polarização eletroquímica dos revestimentos em comparação com o aço descoberto. Ambos os revestimentos apresentam comportamento anticorrosivo em comparação com o aço puro (sem revestimento). ${ }^{22}$

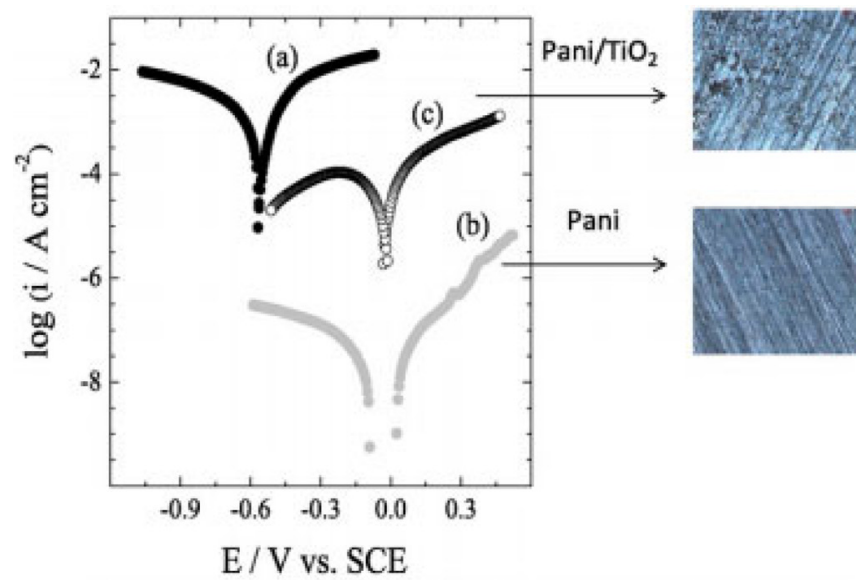

Figura. 3. Curvas de polarização eletroquímica dos revestimentos de PAni-1 e PAni / $n-\mathrm{TiO}_{2}$ em comparação com o aço descoberto ${ }^{22}$

$\mathrm{O}$ revestimento de $\mathrm{PAni} / \mathrm{n}-\mathrm{TiO}_{2}$, é considerado um bom revestimento aderente e anticorrosivo, e foi detectado que houve um aumento na sua adesão ao aço e no seu comportamento anticorrosivo com o aumento de sua espessura de cobrimento, reduzindo assim a porosidade do revestimento. ${ }^{22}$

A melhoria em relação ao revestimento de PAni resultou no aumento da adesão à superfície do aço e, portanto, na maior durabilidade do revestimento. As boas propriedades de aderência ocorreram devido ao processo de nucleação durante a síntese, em que o n- $\mathrm{TiO}_{2}$ atua como semente para a polimerização do PAni, aumentando a adesão quando várias camadas são depositado no aço. ${ }^{22}$

Revestimentos de polianilina e nanopartículas de $\mathrm{TiO}_{2}$ e $\mathrm{ZrO}_{2}$, sintetizados eletroquimicamente em uma liga de alumínio (AA2024T3) por um procedimento de anodização de etapa única em um eletrólito de ácido oxálico, resultaram em uma densidade de corrente passiva duas ordens de grandeza menor do que para o revestimento contendo nanopartículas de $\mathrm{ZrO}_{2}$, e que os revestimentos de $\mathrm{TiO}_{2}$ mostraram sua 
eficiência à proteção contra a corrosão de superfícies metálicas, pelo fato das nanopartículas atuarem como efeito de barreira, dificultando 0 acesso da corrosão à superfície metálica. ${ }^{23}$

As imagens de ampliação aumentadas da Figura 4, mostram superfícies de diferentes morfologias para as ligas tratadas de várias maneiras, para as amostras revestidas com polianilina sem nanopartículas (A2-PA-0), a imagem sugere uma morfologia bastante áspera, que pode ser atribuída à polianilina na superfície (Figura 4 (a)). No caso da amostra revestida com nanopartículas de polianilina e $\mathrm{TiO}_{2}$ (A2-PA-T1), exibidas na Figura 4 (b), uma morfologia de textura relativamente fina é observada, com pequenos grânulos presos, ou cobertos, por uma matriz contínua, com uma aparência de superfície compacta. Presume-se que essa cobertura seja polianilina. ${ }^{23}$

Grânulos brilhantes de cerca de $1 \mu \mathrm{m}$ estão associados com nanopartículas de $\mathrm{TiO}_{2}$, uma vez que, eles são ricos em titânio. Para a amostra revestida com polianilina e nanopartículas de $\mathrm{ZrO}_{2}$ (A2-PA-Z1), uma morfologia finamente granular é evidente (Figura 4 (c)), com numerosos grânulos brilhantes não aprisionados em uma matriz contínua. Esses grânulos brilhantes são ricos em zircônio. Finalmente, a liga tratada na presença de nanopartículas de $\mathrm{TiO}_{2}$ sem anilina (A2-0-T1) mostra uma aparência relativamente uniforme (Figura 4 (d)), sem evidência de grânulos. ${ }^{23}$

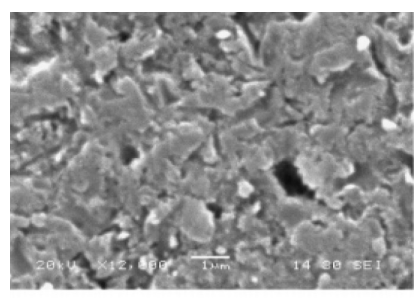

(a)

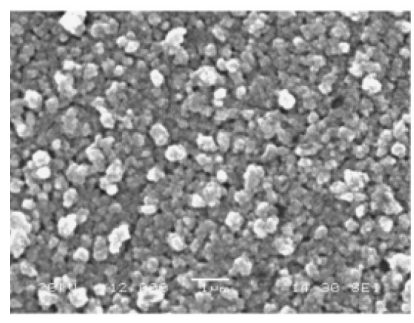

(c)

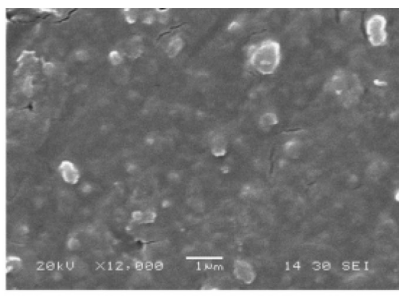

(b)

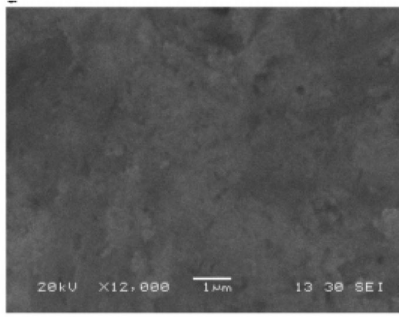

(d)
Figura 4. Micrografias eletrônicas de varredura de alta ampliação da superfície da liga de alumínio AA2024T3 anodizada em meio oxálico com (a) anilina (A2-PA-O), (b) anilina e $\mathrm{TiO}_{2}$ nanopartículas (A2-PA-T1), (c) nanopartículas de anilina e $\mathrm{ZrO} 2$ (A2-PA-Z1) e (d) nanopartículas de $\mathrm{TiO}_{2}(\mathrm{A2}-\mathrm{O}-\mathrm{T1})^{23}$

Os revestimentos de $\mathrm{PAni} / \mathrm{Zn}$ e $\mathrm{PAni} / \mathrm{TiO}_{2}$ e PAni/Ag eletropolimerizados mostraram eficiência de proteção anticorrosiva, por meio de um sistema por camadas fornecendo ao metal proteção contra a corrosão, onde a primeira camada de PAni ajuda a promover o efeito de barreira conferindo a segunda camada de revestimento maior aderência à superfície metálica, onde, os óxidos de cério (III) ou (IV) com nanopartículas de Ag garantem maior estabilização e melhor morfologia do revestimento unido a uma matriz polimérica. Essas conclusões foram confirmadas pela diminuição da permeabilidade ao oxigênio e à água e ao aumento da adesão do revestimento na presença de nanomateriais $\mathrm{TiO}_{2}, \mathrm{Ag}$ e $\mathrm{Zn}$ na PANI. Dessa forma, é possível entender que uma variedade de materiais híbridos ou nanopartículas são utilizados como revestimentos anticorrosivos em superfícies metálicas. ${ }^{24}$

Comparações dos potenciais de corrosão (Ecor) e corrente de corrosão (Icor) de amostras tratadas, em que as amostras tratadas a
$500{ }^{\circ} \mathrm{C}$ de óxidos mistos com $20 \%$ de $\mathrm{ZrO}_{2}$ resultaram em melhor desempenho na inibição contra os processos de corrosão da matriz do $\mathrm{Al}_{2} \mathrm{O}_{3}$, de acordo com os menores valores de Ecor e Icor. ${ }^{17}$

Métodos anticorrosivo de superfícies de ligas de alumínio através de um processo de elaboração de revestimentos não agressivos ao meio ambiente, com base em uma combinação de um sistema composto por nanopartículas de AgCe e o filme de PAni, compondo um revestimento de duas camadas, também apresentaram boa estabilidade para a proteção à corrosão em substratos metálicos. ${ }^{21}$

E ensaios eletroquímicos com amostras com revestimento anticorrosivo mostram valores de potencial de corrosão com valores mais positivos, em que a solução PAni em deposição sobre uma camada de nanopartículas de $\mathrm{AgCe}$ mostrou melhor interação das camadas, apresentando melhor aderência entre o filme e o revestimento de PAni na superfície metálica. ${ }^{16}$

\section{OS REVESTIMENTOS ANTICORROSIVOS}

Os diferentes tipos e métodos de proteção anticorrosivos são escolhidos conforme o tipo de corrosão, a ação dos agentes oxidantes e à eficiência ao metal de base, o processo de corrosão ocorre quando há contato direto do oxigênio com os metais, desta forma, são fabricados diversos tipos de métodos impermeabilizantes que proporcionam proteção anticorrosiva à superfície dos metais. ${ }^{15}$

Os revestimentos metálicos têm a função de impedir o contato da superfície metálica com as substâncias corrosivas, em que é aplicado um revestimento de camada de zinco metálico sobre a base metálica, em processo chamado de galvanização, porém, existem processos de revestimentos não metálicos (tintas), que além de obterem uma função decorativa também podem ser utilizados na proteção de superfícies metálicas. ${ }^{15}$

O uso de materiais poliméricos vem aumentando em uma diversidade de funcionalidades e aplicações técnicas, principalmente pela sua capacidade de se adaptar às propriedades desejáveis. Matrizes termoendurecíveis, como as resinas epóxi, são muito utilizadas devido às altas propriedades mecânicas adequadas para aplicações na construção civil, como revestimentos. Isso se deve aos grupos funcionais encontrados em sua estrutura, como, por exemplo, a resina epóxi vinílica, que é utilizada como uma tinta de revestimento resistente aos ácidos inorgânicos, umidade e corrosão. ${ }^{13,25}$

Um composto químico em pó com aparência alaranjada, chamado de zarcão, de fórmula $\left(\mathrm{Pb}_{3} \mathrm{O}_{4}\right)$, pode ser utilizado como um revestimento ou tinta contra a corrosão de materiais metálicos, muito utilizado para a proteção de portões, esquadrias e brinquedos metálicos de playgrounds. ${ }^{26}$

Outra proteção, também utilizada como um revestimento anticorrosivo, é a galvanização com duplo mecanismo de resistência, por meio de barreira e proteção catódica, na qual o aço carbono é revestido com zinco metálico e uma camada metálica sobre o metal, formando uma barreira anticorrosiva e inibindo o contato. A proteção catódica por meio de galvanização ocorre devido à diferença entre os potenciais padrão de redução do zinco e do ferro. ${ }^{26}$

O aço inoxidável austenítico é um metal que apresenta a característica de formar uma camada passível e apresenta em sua composição uma média de $11 \%$ de cromo, permitindo a formação de uma camada de óxido $\mathrm{Cr}_{2} \mathrm{O}_{3}$ que garante a proteção do material metálico. Continua o autor dizendo que, com a adição de elementos de liga ocorre a melhora das propriedades dos metais, como, por exemplo, a adição dos elementos como níquel silício e molibdênio, lembrando que a quantidade de carbono nos aços inox é baixa, devido ao fato do carbono ser um elemento responsável pela aceleração da oxidação. Dessa forma, o aço inox apresenta uma excelente resistência anticorrosiva. $^{27}$ 
Os materiais poliméricos são uma excelente alternativa para o uso anticorrosivo, sendo que na segunda guerra mundial esse material teve seu uso intensificado na comunidade científica devido às suas propriedades capazes de superar algumas características dos aços, como, por exemplo, as propriedades contra a ação da corrosão. ${ }^{27}$

\section{CONCLUSÕES}

Neste trabalho foi apresentado o estado da arte sobre os materiais híbridos como uma alternativa para revestimentos anticorrosivos de superfícies metálicas, como o aço.

$\mathrm{O}$ aço é um material metálico utilizado em diversos setores industriais, oferecendo soluções que beneficiam a vida dos seres humanos, inclusive para construção de estruturas, devido as suas excelentes propriedades mecânicas, porém, a sua oxidação é responsável pela perda de suas propriedades, tornando-o inviável ao longo do tempo.

Entendendo que o processo de corrosão do aço é resultante de reações químicas, do material com o ambiente, envolvendo o oxigênio, hidrogênio e/ou água, ou como um ataque eletroquímico destrutivo e não intencional de um metal, é possível entender a importância da proteção das superfícies de materiais como o aço, para que ele não perca suas propriedades físicas, químicas e mecânicas e possa ser utilizado em diversas áreas industriais com maior tempo de vida útil possível.

Pesquisas mostram que os materiais híbridos, preparados a partir de nanocompósitos poliméricos, de argila montmorilonita de origem natural, de polianilina (PAni), são capazes de garantir a proteção contra a corrosão, garantindo que os materiais metálicos tenham suas características físicas e químicas integras por um tempo maior.

Alguns processos se apresentam eficazes contra a corrosão dos aços, tais como processos baseados em soluções de ácido fosfórico e com metais dissolvido (zinco, níquel, manganês) e como tratamentos mais ecológicos à base de nanopartículas isentas de metais pesados e fósforo.

Processos preparados com compósitos de PAni/nanotubos$\mathrm{TiO}_{2}$, polianilina e nanopartículas de $\mathrm{TiO}_{2}, \mathrm{ZrO}_{2}, \mathrm{AgCe}$ e PAni/Ag, demonstraram eficiência contra a corrosão de materiais metálicos.

$\mathrm{E}$, por fim, é possível entender que revestimentos elaborados através de processos utilizando materiais híbridos, como a galvanização, zarcão, resinas epóxi, proteção catódica, aço inoxidável austenítico e os polímeros são importantes para aumentar a vida útil de matérias metálicas, como aço, contra o processo de corrosão, diminuindo custos com reparos, desperdício de materiais, mesmo que reaproveitados pela reciclagem, garantindo assim o melhor uso do aço em soluções importantes para a vida do homem na sociedade como para a construção de edifícios.

\section{AGRADECIMENTOS}

Os autores agradecem ao Departamento de Química, ao laboratório Sol-Gel da Universidade de Franca e ao Conselho Nacional de Desenvolvimento Científico e Tecnológico (CNPq, 302702/2018-0 L.A.R., 302668/2017-9 E.J.N. and 306271/2017-6 E.F.M.).

\section{REFERÊNCIAS}

1. Dos Reis Moreira, E. M.; De Farias, B. M.; Souza da Silva, M. H.; Ferreira de Oliveira, B. R.; Portela, F. D. S.; Sousa dos Santos, H. B.; Semioses 2019, 13.

2. Dias, J. M. S.; César, S. F.; Marques, L. S.; Oliveira Filho, F. M.; Cunha, R. D. A.; Reis, M. C.; Revista Ciência (In) Cena 2018, 6, 113

3. Bidetti, B. B.; Balthazar, P. A.; Vaz, E. L. S.; Codaro, E. N.; Acciari, H. A.; Quim. Nova 2012, 35, 634.

4. Sade, W.; Nunes, R. A. X.; Moreira, V. E. de S.; Haneiko, N. B. D.; da Silva, N. N.; Matéria (Rio Janeiro) 2019, 24, e-12278-9.

5. Furtado, P.; Pintura Anticorrosiva dos Metais, $1^{\text {a }}$ ed., LTC: Rio de Janeiro, 2010.

6. Serenário, M. E. D.; Abreu, F. T. De; Souza, R. C.; Santos, B. A. F.; Miranda, R. M. De; Bueno, H. S.; Federal, U.; João, D. S.; Mecânica, D. D. E.; Frei, P.; Rev. Virtual Quim. 2019, 11, 218.

7. Miranda, T. B.; Nanocompósitos de epóxi/Nanopartículas de Carbonato de CÁLCIO: Propriedades Termomecânicas e de Superfície, Universidade Federal de Minas Gerais, 2019.

8. Gil, A. C.; Como elaborar projetos de pesquisa, $4^{\mathrm{a}}$ ed., Ed. Atlas: São Paulo, 2007.

9. de Araújo, L. C. A.; Ribeiro, P. R. da S.; Reznik, L. Y.; Lutterbach, M. T. S.; Sérvulo, E. F. C.; Matéria (Rio Janeiro) 2019, 24, e12295.

10. Chiaverini, V.; Aços e ferros fundidos, $6^{\mathrm{a}}$ ed., Associação Brasileira de Metalurgia e Materiais: São Paulo, 1988.

11. Rodrigues, J. P. C.; Laím, L.; J. Constr. Steel Res. 2019, 153.

12. Marília Evelyn Rodrigues Oliveira; Tese de Doutorado, Universidade de São Paulo, Brasil, 2019.

13. Silva, M. V. F.; Pereira, M. C.; Codaro, E. N.; Acciari, H. A.; Quim. Nova 2015, 38, 293.

14. Araujo, J.; Silva, R.; Milagre, M.; Machado, C.; Costa, I.; Quim. Nova 2020, 43, 1058

15. Pereira, G. E. S.; Trabalho de Conclusão de Curso, Universidade Federal Rural do Semiárido, Brasil, 2018.

16. Silva, H. J. B.; Nascimento, V. A.; Dourado, J. B. O. L.; Santana, M. V.; Oliveira, B. L. M.; Silva, H. D. A.; Rev. INGI 2019, 3, 268.

17. Shabani-Nooshabadi, M.; Ghoreishi, S. M.; Behpour, M.; Electrochim. Acta 2009, 54.

18. Grgur, B. N.; Elkais, A. R.; Gvozdenović, M. M.; Drmanić, S.; Trišović, T. L.; Jugović, B. Z.; Prog. Org. Coatings 2015, 79, 17.

19. Seniski, A.; de Oliveira, T. A.; Portella, K. F.; Carrera, G.; Bragança, M. d'Orey G. P.; Matéria (Rio Janeiro) 2020, 25, 1.

20. Tedim, J.; Kuznetsova, A.; Salak, A. N.; Montemor, F.; Snihirova, D.; Pilz, M.; Zheludkevich, M. L.; Ferreira, M. G. S.; Corros. Sci. 2012, 55 , 1

21. Rodrigues, M.; Del, A.; Frederico, F.; Clayton, A.; Orbital Electron. J. Chem. 2013, 5, 264

22. Pagotto, J. F.; Recio, F. J.; Motheo, A. J.; Herrasti, P.; Surf. Coatings Technol. 2016, 289, 23.

23. Zubillaga, O.; Cano, F. J.; Azkarate, I.; Molchan, I. S.; Thompson, G. E.; Skeldon, P.; Surf. Coatings Technol. 2009, 203, 1494.

24. Ates, M.; Topkaya, E.; Prog. Org. Coatings 2015, 82, 33.

25. Lascano, D.; Valcárcel, J.; Balart, R.; Quiles-Carrillo, L.; Boronat, T.; Ingenius: Revista de Ciencia y Tecnología 2020, 3, 63.

26. Olympio, K. P. K.; Silva, J. P. da R.; Silva, A. S. da; Souza, V. C. de O.; Buzalaf, M. A. R.; Barbosa, F.; Cardoso, M. R. A.; Environ. Pollut. 2018, 240, 831

27. Callister, W. D.; Ciência e engenharia dos materiais: uma introdução, $7^{\mathrm{a}}$ ed., Pearson Prentice Hall: São Paulo, 2008. 